\title{
Design of Small Multifunction Chassis Hydraulic Leveling Device Tengfei $\mathrm{Wu}^{1, \mathrm{a}}$, Tingyv Wang ${ }^{1, \mathrm{~b}}$, Xiaorong $\mathrm{Lv}^{1, \mathrm{C}^{*}}$ and Yan Huang ${ }^{1, \mathrm{~d}}$ ${ }^{1}$ college of machinery and electronics, Sichuan Agricultural University, Ya'an, Sichuan, China \\ a1484671243@qq.com, b964026857@qq.com, 'Ixrxj@suhu.com, d1243018209@qq.com \\ ${ }^{*}$ The Corresponding author
}

Keywords: Small multifunction chassis; Leveling device; Hydraulic; Design

\begin{abstract}
Aiming at the characteristics of hilly and mountains region such as undulating terrain, small field, irregular, steep slopes and multi-bends, etc. and the problem against the mechanization of field operation, the paper designs a kind of small multifunction chassis hydraulic leveling device. The whole structure design of leveling device and the virtual design of key components have been achieved by virtual prototype technology.
\end{abstract}

\section{Introduction}

The mechanization of field operation is in unsmooth development due to the undulating terrain, small field, irregular, steep slopes and multi-bends and other characteristics [1-2] of hilly and mountains region, and the adjustment of walking posture for agricultural machinery in hilly and mountainous area still stays in the stage of hand control by basic operator with prodigious randomness, resulting in that the stability of walking posture control of agricultural machinery becomes the key factor [3-9] to influence the operating quality of agricultural machinery in hilly and mountainous area. A kind of hydraulic leveling device is designed to be installed on the small multifunction chassis, which is mainly adopted with double-layer support structure. When the tractor walks on different ramps, the walking posture of tractor is controlled in real time by the control panel to keep the level of body all the time; when the tractor works on undulating pavement, the mass center position changes a little (mass center position can be adjusted within a certain scope), which signally improves the stability and slope adaptability when the tractor walks.

\section{Overall Structure and Working Theory}

Overall Structure. The leveling device is composed of chassis, middle leveling plate, upper leveling plate, hydraulic cylinder and supporting column and the hydraulic oil valve switch is controlled by the operator to adjust the expansion and contraction of the hydraulic cylinder to achieve the chassis leveling function. The structure chart of leveling device design is shown in Fig.1. 


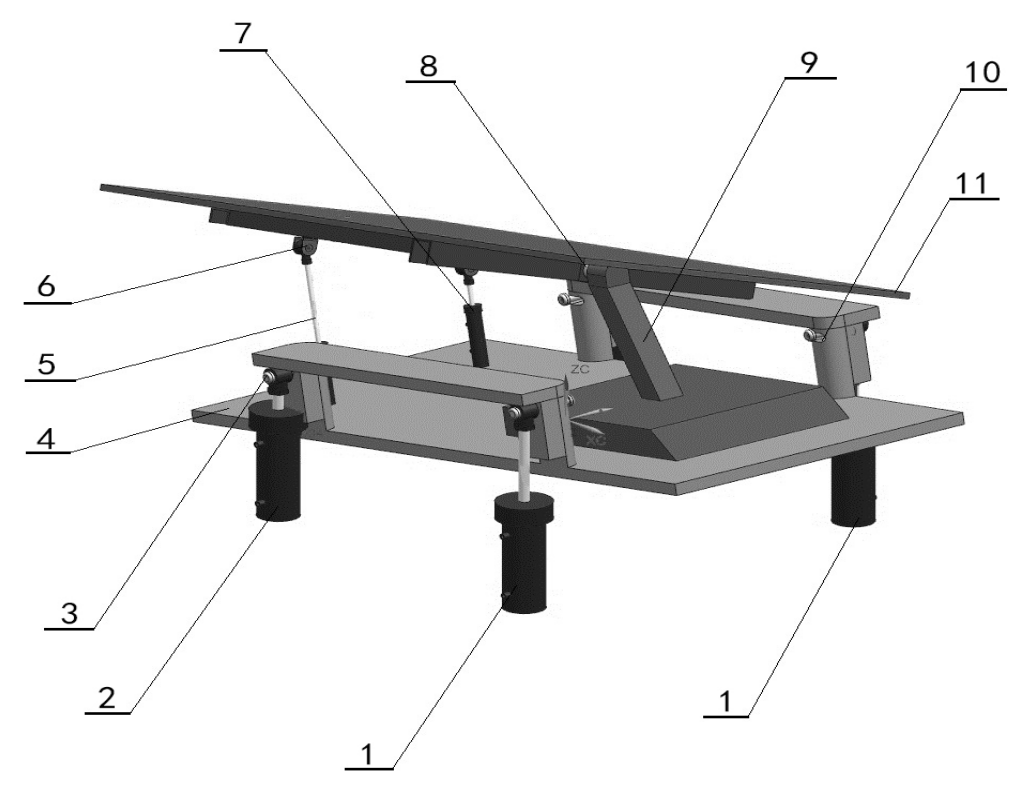

Figure 1. Finite Structure diagram of leveling device

1. Head hydraulic cylinder. 2. Tail hydraulic cylinder. 3. Connecting pin. 4. Middle leveling plate. 5. Upper right hydraulic cylinder. 6. Fittings of leveling plate. 7. Upper left hydraulic cylinder. 8. Rotation axis. 9. Main supporting column. 10. Sliding through-hole. 11. Upper leveling plate.

Working Theory. When the tractor is in the horizontal slope, the hydraulic oil valve switch is controlled by the operator, so that the hydraulic rod of the head hydraulic cylinder (1) and the tail hydraulic cylinder (2) are respectively elongated or shortened, thus making the middle leveling plate (4) and upper leveling plate (11) rotate simultaneously relative to the crawler chassis, but the upper right hydraulic cylinder (5) and upper left hydraulic cylinder will not be rotated. Ultimately, the upper leveling plate (11) will be run parallel with the middle leveling plate (4), and both of all are rotated at an angle relative to the crawler chassis, at the moment, only the crawler chassis (15) is still parallel to the slope, and the upper leveling plate (11), that is, the vehicle body and the middle leveling plate (4) are parallel to the horizontal plane, achieving the leveling function when the body of tractor is in the lateral inclination.

When the tractor is in the longitudinal slope, the upper leveling plate (11), the middle leveling plate (4) and the crawler chassis (15) are in a longitudinal inclined state. The hydraulic oil valve switch is controlled by the operator so that the hydraulic rod of the upper right hydraulic cylinder (5) and the upper left hydraulic cylinder (7) are respectively elongated or shortened, and the upper leveling plate (11) is rotated at a angle around the rotation axis (8) and the crawler chassis (15) and the middle leveling plate (4) are still in a tilted state, but the upper leveling plate (11), that is, the vehicle body, is parallel to the horizontal plane, thereby achieving the leveling function when the tractor body is in the longitudinal inclination.

Similarly, when the tractor is tilted in multiple directions, the hydraulic oil valve switch is controlled by the operator to respectively control the head hydraulic cylinder (1), tail hydraulic cylinder (2), upper right hydraulic cylinder (5) and upper left hydraulic cylinder (7), so that the hydraulic rods of their are respectively elongated or shortened by a certain distance, thus making the upper leveling plate tilt in multiple directions, thereby achieving the leveling function when the body of tractor is tilted in multiple directions. 


\section{Design of Main Working Parts}

Design of main working parts of leveling device designed in this thesis is conducted via virtual three-dimension. A product design environment is provided by virtual design technology, and product design process is optimized, thus powerful support is provided for R\&D of new products [10]. Design quality can be enhanced and design error as well as fabrication cost can be reduced via virtual design technology. Structural design is conducted on parts via UGNX software on basis of above structural scheme of leveling device as well as main technological parameters, aiming at functional requirements and features of all component parts [11].

Design of Double Layer Hydraulic Leveling Mechanism. To ensure the great leveling performance of leveling device, a kind of double-layer hydraulic leveling device with simple structure, small occupation space, flexible operation, reliability and other superior performance is designed, which is composed of the middle leveling mechanism and upper leveling mechanism, and the two leveling mechanisms are connected by a supporting column and two hydraulic cylinders.

Design of Middle Leveling Mechanism. The middle leveling mechanism is composed of head hydraulic cylinder, tail hydraulic cylinder and middle leveling plate, as shown in Figure 2. The head hydraulic cylinder and tail hydraulic cylinder are respectively connected with the four sliding through-holes on the middle leveling plate by closing bearing pin; the closing bearing pin can be slid and rotated in the sliding through-hole; the coordination between closing bearing pin and closing sleeve clearance at the top of hydraulic rod is that the closing bearing pin can be moved together with hydraulic rod; the cylinder bodies of head and tail hydraulic cylinder are fixed on the crawler chassis.
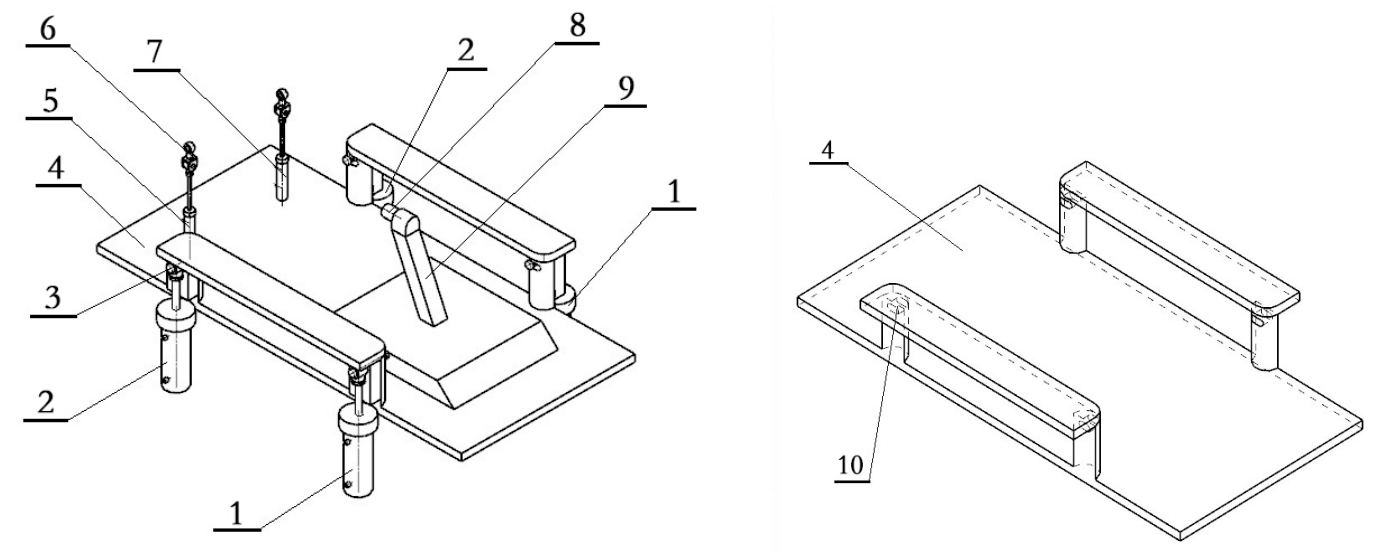

Figure 2. Finite Middle leveling mechanism

1. Head hydraulic cylinder. 2. Tail hydraulic cylinder. 3. Connecting pin. 4. Middle leveling plate.

5. Upper right hydraulic cylinder. 6. Fittings of leveling plate. 7. Upper left hydraulic cylinder. 8.

Rotation axis. 9. Main supporting column. 10. Sliding through-hole. 11. Upper leveling plate.

As shown in Fig. 2, there are four supporting columns fixed around the middle leveling plate, which are respectively placed on the long side of the leveling plate symmetrically, and the distance between same side supporting columns is the half of length of long side of leveling plate. There are four strip sliding through-holes respectively on the four supporting columns, and the length of through-hole is slightly greater than the distance between head hydraulic cylinder and tail hydraulic cylinder, and the width of through-hole is slightly greater than the diameter of closing bearing pin to ensure that the closing bearing pin both can be rotated in the sliding through-hole and can be horizontally moved relative to the sliding through-hole. The middle leveling plate is connected with the cylinder of upper right hydraulic cylinder and upper left hydraulic cylinder, and simultaneously fixed with main supporting column. 
Design of Upper Leveling Mechanism. The upper leveling mechanism is composed of upper right hydraulic cylinder, upper left hydraulic cylinder, main supporting column and upper leveling plate. The main supporting column is connected with the bearing of rotation axis of upper leveling plate through rotation axis, so that the upper leveling plate can be rotated relative to main supporting column. The gusset plate is installed on the upper leveling plate to improve its strength. The axle sleeve of upper right and upper left hydraulic cylinder is connected with the lower end connecting axle base of fittings of leveling plate, and the upper end connecting axle sleeve of fittings of leveling plate is connected with the fixed connecting axle of upper leveling plate.

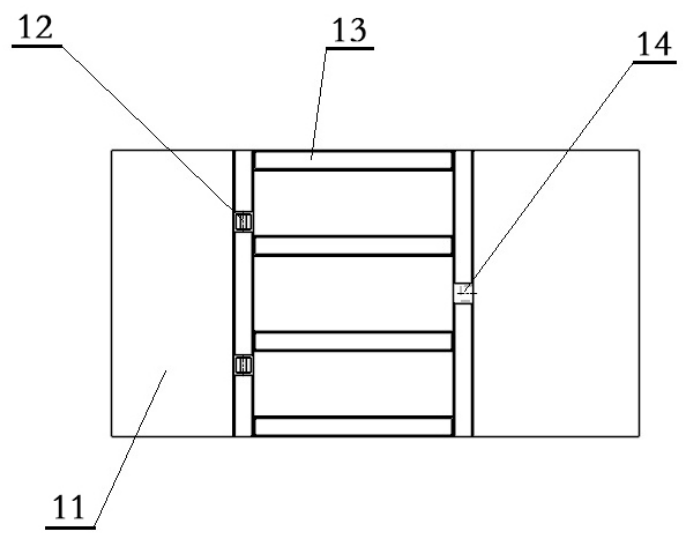

Figure 3. Finite Upward view for structural design of upper leveling plate

11. Upper leveling plate. 12. Fixed connecting axle. 13. Gusset plate. 14. Bearing of rotation axis

Structural Design of Flat Plate Connector. The leveling plate connecting member is composed of the upper connecting sleeve and the lower connecting shaft base. The center line of the upper sleeve is perpendicular to the centerline of the center axis of the lower shaft and the lower end of the shaft is connected to the sleeve on the hydraulic rod so that the leveling plate is rotated relative to the sleeve on the hydraulic rod. And the upper connecting sleeve is connected with the fixed connecting shaft on the upper leveling plate so that the leveling plate connecting member can slide relative to the upper leveling plate.
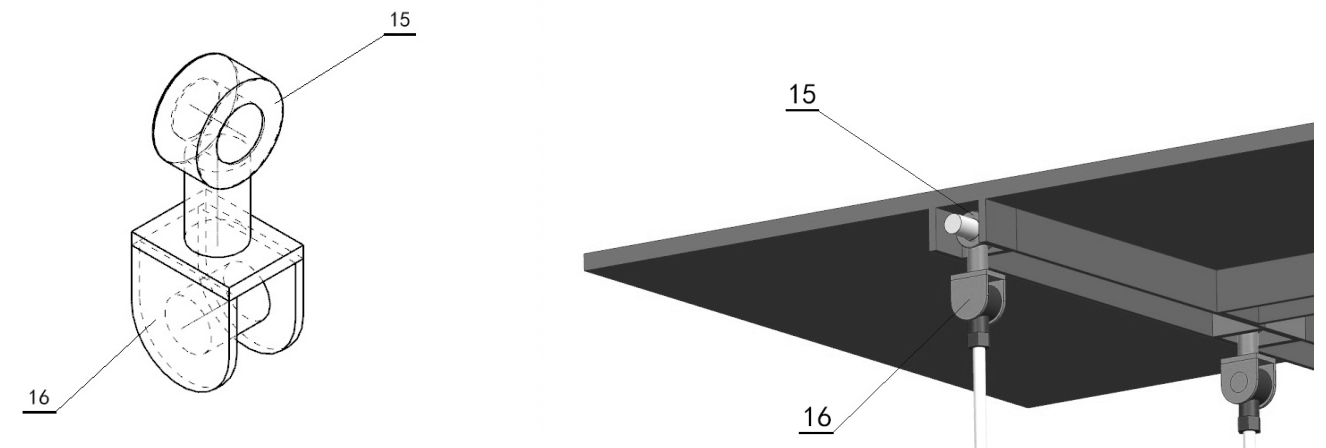

Figure 4. Finite Structural design for fittings of leveling plate

15. Upper end connecting axle sleeve 16. Lower end connecting axle base

\section{The Advantages of Leveling Devices.}

The main connection parts of the design mostly use the pin roll as connection, so leveling equipment is very stable before and after the leveling. Compared with the traditional leveling device, in the process of moving the machine vibration is smaller; leveling device uses double flat plate structure, the upper level adjusting plate and the middle level flat plate work independently, so that 
this equipment can achieve one-way leveling, but also ensure multi-angle leveling at the same time under the premise of the stability of the body. The leveling device using hydraulic cylinder as a support and leveling the original, so that leveling device can withstand a larger load, and leveling process is gentle, with small impact.

\section{Summary}

The paper studies a kind of hydraulic automatic leveling device, with simple and novelty whole structure, small occupation space, light quality and few consumption, and the intelligent leveling function can be effectively achieved by the mechanism within the allowable scope of load, aimed at the small tractor chassis mechanism. This set of device has been successfully applied for national utility model patents, and the design is comparatively suitable to combine with small tractor in hilly area, so that it is stable in walking, with strong passing ability, to achieve the walking on the ramp in different angles to ensure that the tractor safely and stability completes the agricultural operation, which promotes the development of agricultural machinery.

\section{Acknowledgements}

Sichuan province leaders in academic and technical training project funding.

Correspondence Author: Lv Xiaorong, college of machinery and electronics, Sichuan agricultural university,ya'an,china,lxrxj@sohu.com.

\section{References}

[1] Liu Gang, Lin Jianhan, Si Yongsheng, et al. Development and experiment on laser controlled leveling system [J]. Transactions of the Chinese Society for Agricultural Machinery, 2006,37 (1): 71-74.

[2] Zhongji Nanfang Machinery Co., Ltd. An automatic balancing device for transplanter [P]. China Patent: ZL200820133989.3, 2008-09-24.

[3] HE Jin-yi, YANG Fu-zeng, XU Xiu-dong.Design of Control System of Remote Track Micro-tiller in Mountainous Area [J]. Tractors and Agricultural Vehicles, 2011,38 (2): 19-22.

[4] Hu Lian, Lin Chaoxing, Xiwen Luo etc. Agricultural machinery automatic leveling control system design and test [J]. Journal of Agricultural Engineering, 2015, 31 (8): 15-20.

[5] Jiang Fudong, Chen Dexin. China's hilly tobacco industry, tobacco agriculture mechanization development status and countermeasures [J]. Animal husbandry and feed science, 2009,30 (2): 97-99.

[6] Rickman J. F. Manual for laser land leveling [R]. Rice-Wheat Consortium Technical Bulletin Series 5, 2002.

[7] Zhang Ruihong, Dai Guojun, Gu Ling, et al. Design and analysis of multiple working paddy-field land-leveler equipped on tractors [J]. Journal of Jiangsu University, 2004, 25 (6): 465-468.

[8] Xi Zhongping, Bao Xiangdong.Application experiment of hills and mountains in small multi-function machine [A]. Agricultural Engineering, 2012, 4.

[9] Zhang Yun, Xu Min, Bao Xiangdong, Zhang Qianchuan. R \& D to adapt to mountain operations of rice and wheat harvesters is very necessary. Agricultural Science and Technology Extension, 2015 (12): 46-47.

[10]Wu Qunbo, Zhang Linxiao, Xiao Tianyuan, Long Xinhai. Product innovation design under virtual product development environment [A]. China Mechanical Engineering, 2003, 14 (2): 116-119.

[11]Zhang Lihua, Lv Xiaorong. UG NX6.0 computer aided design and manufacturing practical tutorial [M]. Beijing: Peking University Press, 2009, 6. 